\title{
Marianne Lacomblez e a construção de uma Psicologia da Atividade de Trabalho'
}

\author{
Marianne Hélène Lacomblez $z^{\mathrm{I}}$, Anísio José da Silva Araújo ${ }^{\mathrm{II}}$, \\ Paulo César Zambroni-de-Souza ${ }^{\text {II }}$, Thaís Augusta Oliveira da Cunha Máximo ${ }^{\text {II }}$ \\ ${ }^{1}$ Universidade do Porto (Porto, Portugal) \\ ${ }^{\text {II } U n i v e r s i d a d e ~ F e d e r a l ~ d a ~ P a r a i ́ b a ~(J o a ̃ o ~ P e s s o a, ~ P B, ~ B r a s i l) ~}$
}

No ano acadêmico de 2014, Marianne Lacomblez foi professora visitante da Universidade Federal Fluminense (Pósgraduação em Psicologia). Durante esse período, passou um mês no Programa de Pós-graduação em Psicologia Social da Universidade Federal da Paraíba, tendo proferido palestras, participado de orientações de Pós-graduação, reunido-se com grupos de pesquisa e discutido artigos. Na ocasião, concedeu esta entrevista aos Cadernos de Psicologia Social do Trabalho.

Cadernos: Conte-nos um pouco sobre sua trajetória profissional.

Marianne: As problemáticas que trabalhamos hoje com os colegas da equipe que coordeno na Universidade do Porto poderão ser consideradas como integrando aquilo que Jacques Leplat designa de Psicologia Ergonômica. Mas, na segunda metade dos anos 1960, época em que realizei a minha formação com Jean-Marie Faverge, falava-se de Psicologia Industrial e, só depois, de Psicologia do Trabalho, embora a abordagem desenvolvida no âmbito desta tradição não se distinguisse daquilo que atualmente costuma ser designado de Ergonomia da Atividade. Paralelamente a isso, no final do curso em Psicologia (Industrial), comecei a participar de um grupo que se dedicava à formação sindical. Desse grupo faziam parte colegas e docentes desse curso liderado por Faverge na Universidade de Bruxelas, mas também colegas e docentes de outras áreas disciplinares. Resumindo, um grupo muito ligado ao movimento sindical que, nessa conjuntura, era orientado pelos princípios do que se denominava de "controle operário".

\section{Cadernos: Era uma formação para sindicalistas?}

Marianne: Era uma formação visando capacitar sindicalistas em várias áreas, tais como Economia, Sociologia, Direito Laboral, assim como em questões de Saúde e Segurança no Trabalho. Depois, passei a trabalhar, durante alguns anos, como investigadora de uma equipe que se situava entre a Psicossociologia do Trabalho e a Sociologia do Trabalho, o que correspondeu à necessidade que sentia de complementar a minha formação. Acabei, contudo, por assumir uma postura bastante crítica em relação à prática então dominante na Psicossociologia do Trabalho, presa nas 'armadilhas' de uma intervenção nas empresas que acreditava que as vias de uma 'desalienação' poderiam passar por uma gestão bem planejada da dinâmica de grupos restritos. Posteriormente, trabalhei com colegas da Sociologia do Trabalho, quer na Universidade de Bruxelas, quer na Universidade de Coimbra, já após o fim da ditadura 
em abril de 1974. A minha tese de doutorado, defendida em Bruxelas no início de $1984^{2}$, acabou por resultar desse percurso, assumindo a postura teórico-histórica que, no fundo, eu considerava que tinha sido incipiente na minha formação acadêmica. Analisei, de modo particular, o paradigma prevalente/dominante na abordagem das motivações no trabalho. Era, naquele período, um tema muito debatido e objeto de alguma controvérsia, associada às transformações que ocorriam no mundo do trabalho e às mudanças nos modos de gestão, em que se procuravam modos alternativos à organização taylorista-fordista do trabalho. O debate, recorrente nesses anos, convocava as obras de Abraham Maslow e de Frederick Herzberg. O meu projeto foi o de avançar numa arqueologia desse tipo de saber, regressando aos autores que tinham traçado os fundamentos daquele paradigma. Cheguei assim ao século XIX e, mais atrás ainda, através de um longo "passeio" sócio-histórico em busca desses referenciais fundacionais. Nas conclusões da minha tese, avancei com a proposta da constituição de uma Psicologia Clínica do Trabalho. Na verdade, eu estava deste modo a inserir-me num projeto que alguns autores, hoje bem conhecidos no Brasil, já esboçavam: entre eles, Ivar Oddone, Alessandra Re e Gianni Briante - com a publicação em 1977 na Itália ${ }^{3}$ do livro Esperienza operaia, coscienza di classe e psicologia del lavoro - e, em 1981, na versão em francês desta obra, aliás, prefaciada por Yves $\mathrm{Clot}^{4}$. Podemos dizer que essas questões e dúvidas começavam a estar em evidência naquela época. É de registrar que os primeiros trabalhos de Christophe Dejours também emergem nesses anos e Yves Clot passou a propor uma Clínica da Atividade. É nesta perspectiva que privilegiei, em seguida, aquilo que venho designando de uma abordagem "navilleana", em referência às contribuições de Pierre Naville que, após vários anos de prática como psicólogo do trabalho, nos anos que rodeiam a segunda guerra mundial, tornou-se um dos maiores sociólogos do trabalho franceses. Pierre Naville defendia, de forma correta, que esta distinção entre Psicologia do Trabalho e Sociologia do Trabalho não tinha sentido. Portanto, é esta a minha trajetória, justificando de maneira muito sintética o porquê de certas referências teóricas.

Cadernos: Em relação a essa sua redefinição do que costuma agora designar de Psicologia da Atividade de Trabalho, neste percurso, você já reavaliou alguma coisa face à formação de base do fim dos anos 1960 ?

Marianne: Sim, bastante. Passando por esta abordagem, que eu designei de "navilleana", que tornou indispensável a consideração das evoluções das nossas sociedades, das relações laborais, enfim, de tudo o que caracteriza uma abordagem sociológica do trabalho.

Cadernos: Você fez uma referência ao Ivar Oddone. Poderia falar mais sobre a importância dele ou de outros autores em sua trajetória?

Marianne: Posso dizer hoje que, paradoxalmente talvez, a referência aos colegas italianos passou a ser essencial a partir da minha experiência em Coimbra, onde participei numa equipe pluridisciplinar que criou (criamos), na segunda metade da década de 1970, o Centro de Estudos Sociais (CES), centro de investigação liderado por Boaventura de Sousa Santos. Esta experiência de trabalho coletivo com colegas de diversas formações e áreas científicas, inseridos em tradições científicas às vezes divergentes, me permitiu, sem dúvida, dar

\footnotetext{
2 Sintetizada em: Lacomblez, M. (1986). Lanalyse des motivations de l'homme au travail: archéologie d'un paradigme dominant. Critique Régionale (Le travail en Sociologie), 14, 91-128. Ver também: Lacomblez, M. \& Maggi, B. (2000). Prendre le temps de lire le temps dans les recherches de Hawthorne. In G. de Terssac \& D. G. Tremblay (Orgs.), Où va le temps de travail? (pp. 49-63). Toulouse: Octarès.

3 Oddone, I., Re, A., \& Briante, G. (1977). Esperienza operaia, coscienza di classe e psicologia del lavoro. Torino: Einaudi.

4 Oddone, I., Re, A., \& Briante, G (1981). Redécouvrir l'expérience ouvrière: vers une autre psychologie du travail? Paris: Éditions Sociales.
} 
um salto decisivo no olhar em relação ao que havia adquirido com a minha formação e experiência anteriores. Foi a partir daí que defini progressivamente a temática da minha tese de doutorado, do meu projeto, centralizando-me na questão de como se faz ciência, como se fez e como se faz, na minha área e em áreas afins. É importante essa questão da consciência de que todo conhecimento é produzido/construído: como? Em que tipo de conjuntura? Com que tipo de dados? Com que finalidade? E é obvio que o que Ivar Oddone costumava relatar, a propósito da sua experiência como médico, ia ao encontro deste questionamento. $\mathrm{O}$ que mais ficou na minha memória, quando me lembro dele, é o que contava do momento em que teve consciência da inutilidade dos seus conhecimentos científicos no âmbito do seu diálogo com os trabalhadores e os militantes sindicais. Era a racionalidade da estrutura do seu saber como médico que era questionada - porque não permitia analisar e interpretar a evolução do estado de saúde dos operários que o consultavam. Só se tinha acesso a uma lista de substâncias nocivas e nada sobre as condições de produção, nem sobre como substituir um processo de produção por outro sem consequências humanas desastrosas. Para ele, jovem médico recém-formado, o uso da literatura médica tinha como finalidade essencial a eliminação das condições de nocividade. Mas, na realidade, não o permitia. Foi a partir dessa tomada de consciência que reorientou a sua atividade e os projetos de toda uma geração de investigadores e militantes para a elaboração de modos alternativos de sistematização dos dados da experiência operária, no âmbito de um outro tipo de "interface" entre os conhecimentos científicos e os conhecimentos detidos pelos trabalhadores. É aí que temos as raízes da célebre "comunidade científica alargada"'.

Mas, no início dos anos 1980, a minha curiosidade orientava-se sobretudo para a história da Psicossociologia do Trabalho, pois tinha descoberto que acumulara muito material para investigar essas perguntas. Hoje em dia (atualmente), tenho verificado que a Psicossociologia do Trabalho no Brasil vem tendo um sucesso particular. Não deixa de ser interessante constatar que passaram a ser referências privilegiadas para os colegas brasileiros alguns autores que conheci nos anos 1970 e que, naquela altura, também assumiam uma postura crítica face ao discurso e à prática bastante ambíguos da Psicossociologia. Esta ambiguidade tinha muito a ver com o que tentei esclarecer na análise da Psicossociologia dos anos 1930/1940, isto é, uma abordagem cuja finalidade fundamental, que mobilizava grande parte dos autores americanos (cujo nome mais conhecido é talvez o de Elton Mayo), era de se contraporem aos contributos das análises marxistas. Foi a partir daí que também percebi a importância de construir um projeto definido em autonomia face aos princípios da Economia Política (na sua concepção clássica). Porque aquelas abordagens, que passei a criticar e que também sustentaram o desenvolvimento da Psico(socio)logia das Organizações, são abordagens epistemologicamente dependentes das categorias de análise da Economia Política - por exemplo, pela importância atribuída à "organização" nas nossas sociedades (tida, no âmbito desta abordagem, como ponto de ancoragem essencial das dinâmicas sociais), ou pela análise da relação com o trabalho entendido essencialmente pelo prisma das "leis" da oferta e da procura.

Cadernos: Perspectivas comprometidas também com o capital.

Marianne: Comprometidas claramente, mas não só isso. $O$ que tentei trabalhar, compreender melhor, não foi apenas o comprometimento das investigações e das suas preocupações privilegiadas. $O$ que me pareceu fundamental foi tentar evidenciar as consequências em termos conceituais. Por isso, importante para mim é a forma como pretendo diferenciar a Psicologia da Atividade de Trabalho da Psico(socio)logia das Organizações em seu paradigma ainda hoje dominante. Nesta linha, o que me mobilizou foi a crítica das abordagens que pretendem definir, de uma vez por todas, as designadas "leis" da natureza humana e que,

5 Pordeus Muniz, H., Brito, J., Reis de Souza, K, Athayde, M., \& Lacomblez, M. (2013). Ivar Oddone e sua contribuição para o campo da saúde do trabalhador no Brasil. Revista Brasileira de Saúde Ocupacional, 38 (128), 280-291. 
com essa postura, acabam, em geral, por considerar os "recursos humanos" (ou a desagradável noção de "capital humano") como objetos de pesquisa e de intervenção (e não como sujeitos, protagonistas), privilegiando opções metodológicas que as conduzem a se afastar do "real", da vivência do dia a dia. Bom, daí o interesse por todo o trabalho que, de fato, ficou sintetizado no livro (Se) former pour transformer le travail: dynamique de constructions d'une analyse critique du travail, que coordenei com Catherine Teiger ${ }^{6}$.

Cadernos: O que constitui o "Paradigma da formação dos atores na e pela análise do trabalho para e pela ação”, que se apresenta nesse livro?

Marianne: A concepção epistemológica e ética que está na base dessa perspectiva, quase inédita até os anos 1960/1970, funda-se no reconhecimento dos saberes que são próprios aos operadores (dita por alguns: "expertise operária") e na relevância de levar (ter) em conta o ponto de vista destes últimos. Ela assenta-se ainda na necessidade de colocar em comum e de confrontar os conhecimentos científicos, os conhecimentos da experiência dos trabalhadores e de seus representantes. Parte-se do princípio de que o debate deveria alcançar, pouco a pouco, uma "descrição compartilhada" dos fenômenos em jogo, contribuindo para o balanço crítico dos conhecimentos científicos convocados, para a renovação das representações veiculadas pelos protagonistas do trabalho e ainda para a definição de ações e intervenções a considerar. Algumas das pesquisas empreendidas permitiram assim associar os operadores, que praticaram auto-observações ou auto-medições preparadas com os pesquisadores. Um vai e vem constante - às vezes formalmente instituído, entre as abordagens de uns e de outros - que permite a cada um construir ou enriquecer as hipóteses, discutir e validar os resultados obtidos (a partir das observações, entrevistas e medidas planejadas em comum). Os conhecimentos produzidos beneficiam-se, assim, de um duplo reconhecimento já que são difundidos e são objetos de debate, sob formas apropriadas, no meio sindical, por um lado, e no mundo científico, por outro. Essa co-aprendizagem, a propósito de um objeto de estudo comum, enquadra estas experiências no campo da pesquisa-ação. Progressivamente, os grandes princípios que guiaram as práticas implementadas foram formalizados ${ }^{7}$, constituindo o corpus fundamental do paradigma colocado em prática - que se chamará "paradigma da formação dos atores na e pela análise do trabalho para e pela ação". O ponto de vista geral destaca evidentemente a questão problemática das relações pensamento-ação, inscritas em uma dupla tradição, filosófica e epistemológica, presente na perspectiva construtivista piagetiana, segundo a qual todo conhecimento consiste não apenas na capacidade de "copiar o real, mas de agir sobre ele e transformá-lo, em aparência ou em realidade, de maneira a compreendê-lo" ${ }^{8}$. Mas esta tradição aposta também na tomada de consciência e na evolução das representações. Definida enquanto conceito "mediador" entre cognição e ação, a representação é aqui entendida enquanto motor potencial de uma ação de mudança da situação. A temporalidade da ação é, portanto, central, orientando a organização de diferentes fases da formação a partir das descrições do trabalho e das questões expressas pelos participantes. Trata-se de uma formação "oportuna", procurando, na medida em que se desenrola, provocar uma atividade reflexiva pela confrontação das representações e dos conhecimentos trazidos por todos. Além da construção de novos conhecimentos, a análise da atividade de trabalho e suas ligações com a saúde, no sentido amplo, sustentam o processo de tomada de consciência individual e coletiva, que deveria permitir a elaboração de "um outro possível" no dia a dia de trabalho.

6 Teiger, C. \& Lacomblez, M. (Coord). (2013). (Se) former pour transformer le travail: dynamique de constructions d'une analyse critique du travail. Québec/Bruxelles: Presses de l'Université Laval/PUL/European Trade Union Institute/ETUI.

7 Ver uma síntese dessa evolução em: Lacomblez, M. \& Teiger, C. (2006). Ergonomia, formações e transformações. In P. Falzon (Ed.), Ergonomia (pp. 587-602). São Paulo: Edgard Blücher.

8 Piaget, J. (1973). Biologia e conhecimento: ensaios sobre as relações entre as regulações orgânicas e os processos cognoscitivos . Petrópolis, RJ: Vozes, p. 15. 
Espera-se que este tipo de intervenção permita a emergência:

-de ligações, entre trabalho e saúde, não aparentes e, às vezes, insuspeitas e impensáveis espontaneamente, que adquirem outra visibilidade e tornam-se "dizíveis" e compartilháveis;

-de conceitos explicativos que, a partir das verbalizações dos atores sobre a sua própria prática de trabalho e sobre suas repercussões, são desenvolvidos em função do avanço da reflexão coletiva e não segundo um programa predefinido pelo formador;

-de uma co-construção de conhecimentos novos sobre a situação e sobre si mesmo, graças ao próprio exercício de reflexão e de expressão, podendo esta construção continuar muito além da própria sessão. Se as duas modalidades de conhecimento são colocadas, desde o início, como tendo ambas a sua legitimidade, é porque elas são concebidas como complementares segundo o princípio de que nenhuma delas sozinha é capaz de esgotar a questão do trabalho.

Este cenário de formação acaba então por constituir-se em um processo de aprendizagem mútua e não numa situação didática clássica de transmissão de conhecimentos. Nesse processo, o coletivo exerce um papel fundamental no questionamento, na confrontação, na deliberação, no acordo ou no desacordo. A polifonia é deliberadamente procurada neste projeto guiado pela vontade comum de transformação das condições da atividade profissional, consideradas inaceitáveis. O objetivo prioritário é o da descoberta e da apropriação de um percurso pelos participantes, em benefício destes, e não unicamente o de uma contribuição ao progresso de uma disciplina científica - mesmo se a riqueza da experiência abre as portas a projetos inéditos para a pesquisa.

A apropriação dos conceitos e métodos da análise do trabalho passa assim a ser considerada como a aquisição de uma "ferramenta cognitiva", tida como capaz de facilitar a iniciativa e a conduta da ação, ou pelo menos a intenção de ação, que depende, obviamente, de outros fatores contextuais. Tal ferramenta assumirá uma função mais ampla, de tipo "desenvolvimental", permitindo adquirir um melhor domínio geral de um ofício ou de uma função, o que pode transformar igualmente a relação com o trabalho e favorecer a saúde, na ótica dinâmica da sua "construção".

Cadernos: Esse livro tem um subtítulo "dynamiques de constructions d'une analyse critique du travail". Qual é o seu propósito?

Marianne: Esse subtítulo revela o que há de transversal aos textos dos 73 autores, europeus, canadenses, venezuelanos e brasileiros, que contribuíram para este balanço. Na realidade, trata-se de uma publicação que resultou de vários encontros - entre pesquisadores, sindicalistas, especialistas da prevenção de acidentes do trabalho e de doenças profissionais que, nos últimos 20 anos, permitiram cruzar relatos de experiências e enriquecer a reflexão. Entre esses autores, encontramos ergonomistas, psicólogos e sociólogos do trabalho, economistas, filósofos - o que não deixa de ir ao encontro do meu percurso anterior. Como, aliás, o fato de eu ter trabalhado bastante com Catherine Teiger, que tive a sorte/felicidade de conhecer pouco tempo após ter concluído a minha tese. Tivemos logo muita afinidade: mesmo tipo de formação, de perspectiva, de experiência em projetos sindicais de ação/transformação do trabalho - embora ela, já com longa experiência de pesquisadora na equipe de Alain Wisner e com um referencial teórico já bem apurado (nomeadamente, graças ao trabalho comum com Antoine Laville) na área deste tipo de intervenção. Foi o mesmo tipo de afinidade que caracterizou o nosso encontro com Ivar Oddone (a quem dedicamos o nosso livro), Alessandra Re e com muitos dos outros autores dessa publicação. Portanto, afinidades que acabaram por sustentar um trabalho coletivo, experiências individuais em um contexto particular que suscitaram, sem dúvida, práticas novas e avanços teórico-metodológicos. Queria sublinhar também aqui a especificidade deste 'contexto particular'. Não é por acaso que este paradigma 
emerge nos finais dos anos 1960 do século passado: em vários lugares do mundo, assistimos à definição de projetos de intervenção deliberadamente ancorados no 'concreto', no 'local', e sustentados pela convicção de que existem diferentes tipos de conhecimento, diferentes modos de explicitá-los, recorrendo a uma grande variedade de linguagens (e discursos). Naquele período se lançam as premissas da valorização da diversidade, da recusa das categorias que legitimariam as hierarquias sociais, do questionamento de uma monocultura do conhecimento que pretenderia transformar a ciência moderna numa verdade única - com a condição que se mantenha conforme a certas normas e cenários do que considerou ser próprio (essência) à produção científica. Foi por esta razão que muitos outros campos de intervenção foram objeto de reflexão e de abordagens que adotaram o mesmo tipo de postura face ao significado potencial do ato concreto: um ato que pode, à primeira vista, parecer banal; mas cuja riqueza se revela fundamentalmente heurística, abrindo a análise para novas ambições susceptíveis de ajudar a transformar a história, o drama individual, numa 'matéria' essencial para a história coletiva. Este postulado é central na obra de vários filósofos da época, e nomeadamente na de Jean-Paul Sartre. Também constitui a base da postura assumida nos anos 1970 por Michel Foucault, quando convida a considerar o 'poder', não como qualquer coisa que 'é', mas sim como qualquer coisa que 'está a ser feita', em estreita articulação com o que está a acontecer, através de uma multiplicidade de dispositivos, mas igualmente de decisões e opções. Contudo, sem nunca esquecer o 'global', pois nessas análises, os dois níveis, do 'local' e do 'global', são indissociáveis: o que justifica a presença nos nossos estudos dos dois polos.

Cadernos: Esses encontros e colaborações estimularam o pensamento, de certa maneira, para se aproximar da atividade e para continuar a abrir alternativas para o que a Psicologia produzia no momento.

Marianne: Certo. E, obviamente, isto justificou depois colaborações com colegas que se inscrevem na tradição definida por Yves Clot, a da Clínica da Atividade. Parece-me igualmente importante realçar que as nossas disciplinas científicas foram renovadas também graças às questões levantadas pelos movimentos sociais, como vimos pelo diálogo construído com os sindicatos. Outro exemplo é o das reflexões suscitadas pelas diversas formas de feminismo. Trata-se, no fundo, de assuntos emergentes na controvérsia social, que evidenciam questões que não são dependentes da ortodoxia científica, mas que nós, cientistas sociais, já não podemos negligenciar nas nossas análises. Embora eu nunca houvesse me envolvido em movimentos feministas, já há alguns anos faço parte de uma rede internacional designada "Gênero, Atividades, Saúde" (GAS), para a qual alguns contributos foram decisivos, nomeadamente o de Catherine Teiger, por ter realçado que grande parte das pesquisas fundadoras da Ergonomia foram realizadas com trabalhadoras, embora usando sempre o 'neutro-masculino' para referi-las'; ou o de Karen Messing pelos seus estudos a propósito do que diferencia, concretamente, as condições de trabalho dos homens e das mulheres insistindo sempre na pergunta: será a ciência cega? ${ }^{10} \mathrm{E}$, na verdade, o trabalho coletivo desta rede tem vindo a confirmar e a reforçar o que acabo de sublinhar.

Cadernos: Você poderia nos explicar um pouco como a questão de gênero foi adquirindo importância nas suas pesquisas?

Marianne: Sempre considerara que, ao abordar as questões do trabalho, não havia razão para privilegiar uma categoria particular de trabalhadores. Para mim, era sem mais valia

\footnotetext{
9 Teiger, C. (2006). "Les femmes aussi ont un cerveau!" Le travail des femmes en ergonomie: réflexions sur quelques paradoxes. Travailler, 1 (15), 71-130.

10 Messing, K. (2000). La santé des travailleuses: la science est-elle aveugle? Montréal: Éditions du remue-ménage. Toulouse: Octarès.
} 
levar em conta essas questões na minha prática profissional de docente e investigadora. Mas mudei. É verdade que também o mundo do trabalho mudou e as questões levantadas são hoje diferentes. As questões da interação entre vida no trabalho e vida fora do trabalho passaram a ser cruciais, essencialmente pelo que é cada vez mais exigido em termos de disponibilidade temporal. $\mathrm{O}$ fenômeno atinge grande parte das profissões. Traz, contudo, questões particulares às mulheres, já que continuam, em geral, a cumprir o essencial das tarefas em casa. Mas o fato acaba por sustentar níveis de remuneração mais baixos, limites na progressão da carreira profissional e mesmo reconfigurações que põem em causa uma gestão decente do tempo de trabalho, ou redefinição de estatutos que foram frutos de longas lutas dos profissionais e que, experimentadas primeiro com mulheres, se estendem, são impostas depois a todos os trabalhadores. Portanto, são questões que, na realidade, têm relação com o evoluir do trabalho.

Cadernos: E que hoje você reconhece que merecem o foco.

Marianne: Como disse, eu sempre estive muito renitente (ou talvez reticente?) em trabalhar as interações entre trabalho e vida fora do trabalho, em invocar aspectos externos ao trabalho para explicar dificuldades que certas pessoas podiam ter no desempenho de sua atividade. Isso fez com que eu sempre pensasse que não é o que está fora do trabalho que nos interessa. Contudo, a dessincronização dos tempos sociais e familiares a que assistimos hoje obriga-nos a não ignorar o 'tempo de não trabalho', contribuindo, sem dúvida, para evidenciar fatos que corriam o risco de ficar, como costuma dizer Yves Schwartz, na 'penumbra do residual'. Na realidade, várias circunstâncias foram bastante determinantes da emergência do meu interesse pelas questões de gênero ${ }^{11}$. Entre elas, a possibilidade, em Portugal, de conseguir financiamento para contratar jovens investigadoras e desenvolver pesquisas nesta área, inserindo o projeto no trabalho desenvolvido pela rede GAS. Isso permitiu conhecermos melhor alguns contributos, como o de Danièle Kergoat e o seu recurso aos conceitos de consubstancialidade e de coextensividade das relações sociais - o que permite compreender, de maneira não mecânica, as práticas sociais de homens e mulheres diante da divisão social do trabalho em sua tripla dimensão: de classe, de gênero e origem (Norte/Sul) ${ }^{12}$. Além disso, a descoberta de obras como a da norte-americana Nancy Fraser, particularmente a sua interpretação da história dos movimentos feministas paralelamente à evolução do mundo do trabalho. Sublinho aqui o fato de a ter lido pela primeira vez pela via de uma revista brasileira que editou a tradução de um seu artigo publicado em inglês ${ }^{13}$. E, insisto nisso, porque penso que no Brasil assistimos a um modo original de estimular o debate entre as contribuições de autores que nem sempre são convocados da mesma maneira na reflexão dos cientistas sociais europeus.

Cadernos: A sua perspectiva tenta sempre evidenciar a normatividade dos humanos que a atividade traz o tempo todo?

Marianne: Podemos formular desse modo e vem daí também o meu interesse pela Ergologia. Ultimamente o que me interessa de modo particular na Ergologia corresponde ao programa do seminário ministrado por Yves Schwartz, quando esteve no mês de setembro de 2013 no Rio de Janeiro, sobre o tema das epistemicidades. Acho particularmente interessante essa questão dos vários níveis de epistemicidades. Para mim, faz todo o sentido tendo em conta a postura crítica que assumi face, por exemplo, à Psico(socio)logia das Organizações, disciplina que, de fato, na sua concepção dominante, se situa no terceiro tipo de epistemicidade (ligados à

11 Sintetizado em: Lacomblez, M. (2014). Quand les horaires de travail se conjuguent douloureusement au féminin. In R. Bercot (Ed.), La santé au travail au prisme du genre: épistémologie, enquêtes et perspectives internationales (pp. 89-103). Toulouse: Octarès.

12 Ver, entre outros: Kergoat, D. (2010). Dinâmica e consubstancialidade das relações sociais. Novos Estudos CEBRAP, 86, 93-103.

13 Fraser, N. (2009). O feminismo, o capitalismo e a astúcia da história. Mediações, 14 (2), 11-33. 
atividade humana) pretendendo, contudo, integrar-se no segundo, em um nível de epistemicidade normativo, prescritivo. $\mathrm{O}$ encontro com a Ergologia é um encontro também feito de grande cumplicidade e é uma contribuição importante para mim. Não mudou grande coisa nas características da minha abordagem, mas me enriqueceu no plano da conceitualização. Todavia, tenho de sublinhar que o trabalho levado a cabo pela Liliana Cunha, no âmbito da preparação da sua tese de doutoramento ${ }^{14}$, foi decisivo para a compreensão profunda do projeto de Yves Schwartz e da (sua) Ergologia. E, agora, com a recém-nomeação de Liliana como professora da nossa equipe, esta vertente de formação dos nossos estudantes ficará bem reforçada.

Cadernos: Numa abordagem que você com seus parceiros de trabalho já vinham desenvolvendo, não é?

Marianne: De fato, trata-se de uma contribuição bastante proveitosa/positiva porque vai além dos princípios que, para nós, já eram adquiridos. E penso que vai ao encontro dos contributos mais recentes de Boaventura de Sousa Santos acerca daquilo que ele designa de Epistemologias do Sul. Sendo o Sul entendido não como um conceito geográfico, mas como o princípio crítico central contra uma racionalidade que pretende ser a única, que tem a pretensão de impor conceitos, análises, metodologias etc. Tais contribuições têm ajudado a caracterizar e a sistematizar o trabalho teórico que desenvolvemos anteriormente, enriquecendo-o, aprofundando-o, dando-lhe mais sentido e mais força.

Cadernos: Embora você não tenha falado, a obra do Marx permanece como pano de fundo, como algo presente em seu trabalho?

Marianne: Tem sim a sua importância, mas sem relação de subordinação, apreciando e gostando de debates contraditórios que podem (e devem) ser feitos. Sou talvez marxiana e não marxista. Penso que é um contributo que tem as suas limitações, já bem antigo e que, em algumas das suas dimensões, tem sido atualizado e prolongado por outros contributos. Não tenho dúvidas sobre isso! Contudo, para mim, continua a ser uma obra à qual me refiro de forma constante, explicitamente ou não. Pois, considero, antes de tudo, que ajuda a perceber/entender a sociedade em que vivemos e muitos dos seus mecanismos, no âmbito da qual o trabalho (quer "abstrato", quer "concreto") continua a revestir uma importância central e simultaneamente problemática (conflitual). Também não tenho dúvidas quanto a isso. O que me irrita é quando sinto e constato que há referências à obra de Marx porque "tem que ser" ou porque "deve ser". Isso irrita-me, mas sobretudo me assusta.

Cadernos: Que métodos em análise do trabalho vêm sendo desenvolvidos e como tem sido conduzida a formação de psicólogos do trabalho na Universidade do Porto?

Marianne: Tudo isso não é alheio, claro, às condicionantes externas, normas europeias e nacionais, negociações com os colegas mais próximos na definição e redefinição dos currículos dos estudantes. Todavia, há alguns princípios básicos que pretendemos sempre salvaguardar, apesar das evoluções dos currículos dos cursos. Assim, é essencial lembrar, desde já, o que corresponde ao nosso postulado de partida: a ausência de visibilidade social da centralidade do trabalho na história individual e coletiva e a convicção de que tal fato não é independente da necessidade de melhorar as condições de emprego e de trabalho. Daí o lugar

14 Cunha, L. (2012). Mobilidades, territórios e serviço público: debates sobre o interesse colectivo à margem do paradigma de uma sociedade móvel. Laboreal, 9 (2), 44-51. 
de destaque que atribuímos à análise da atividade de trabalho e dos seus determinantes. É também revelador de um projeto científico que não se inscreve numa esfera de neutralidade e recusa os "diktats" de uma epistemologia normativa (a ciência tal como deve ser feita), insistindo na necessidade de manter sempre aberto o debate relativo à produção de conhecimentos (a ciência tal como se faz). Tentemos então esquematizar os principais eixos do paradigma que pretendemos privilegiar nos vários níveis de formação dos estudantes:

- Obviamente, a ancoragem no 'real' da 'atividade'; de notar que, ao insistir na especificidade de cada atividade, acabamos necessariamente por afastar-nos de uma análise da relação com o trabalho vista como expressão de leis comportamentais de uma dada natureza humana;

-Procurar ir além da 'fachada' do 'discurso' consensual dos nossos interlocutores;

-Nunca limitar a coleta de verbalizações ao que pode exprimir a 'consciência' individual num dado momento: sempre associá-las a dados recolhidos a partir das situações concretas de trabalho e inscritos num período de tempo significativo;

-Articular o ‘sincrônico' e o ‘diacrônico' (o ‘local' como expressão do 'global');

-Privilegiar a análise comparativa (não há investigação sem comparação);

-Manter uma vigilância epistemológica constante (criar condições que salvaguardem a capacidade de reflexão a propósito das condições que viabilizam ou impedem o desenvolvimento do projeto de intervenção e da produção de conhecimentos); exercitar a capacidade crítica, o debate, a controvérsia face aos interlocutores das pesquisas/intervenções e face aos autores referidos;

-Lembrar o princípio da recursividade da cognição (dos investigadores e dos seus protagonistas), reconhecendo a pertinência dos saberes não acadêmicos;

-Primum non nocere (em primeiro lugar, não prejudicar ninguém).

Convém realçar que este projeto de formação está estreitamente associado ao projeto de uma intervenção, tendo esta, sempre, o estatuto de uma pesquisa. Mas uma pesquisa não submetida essencialmente a intenções de desenvolvimento econômico de curto prazo. A análise da atividade das mulheres e dos homens envolvidas/os conduz a levantar questões que ultrapassam as fronteiras da empresa: em termos de efeitos do trabalho na saúde e em termos de saúde pública ${ }^{15}$; em termos de reconhecimento social da experiência profissional e de identidade cultural local e até, no caso de certas atividades, em termos de relação duradoura com a 'natureza' e de desenvolvimento local.

Cadernos: Sobre análise comparativa, é no sentido de comparar que elementos?

Marianne: Faverge insistia bastante sobre esse princípio e lembrava a obra de Gaston Bachelard. Eu acredito que a comparação sustenta o espírito crítico, a aquisição da distância indispensável à análise. Mas a comparação permite também confrontar os fatores de especificidade e evidenciar alternativas - entre a organização do trabalho de duas equipes, de manhã, de tarde, ou de noite; ou entre duas situações de trabalho semelhantes, mas definidas em contextos diferentes. Por isso, nas nossas teses de doutoramento nunca há um só terreno de investigação.

Cadernos: Essa comparação ocorre apenas com participantes ou também com as ferramentas metodológicas? 
Marianne: É frequente os instrumentos das pesquisas terem as suas particularidades. Não são duas situações de laboratório predefinidas de modo idêntico. Inevitavelmente, nas pesquisas de campo há variações nos condicionalismos, que acabam por interferir no projeto do investigador, no sentido de orientar a intervenção e encaminhar a produção de conhecimentos para determinadas vias. Também por isso é indispensável salvaguardar o máximo de consciência possível sobre esses elementos.

Cadernos: Por isso a expressão "vigilância" sobre o que se passa tanto no campo quanto na maneira como o pesquisador se conduz e as abordagens que elege?

Marianne: Sim, e o trabalho que temos de orientação, de supervisão, de discussão é isso. É também deixar os colegas comentarem, por exemplo, porque não se fez tal opção. E, a partir daí, o que nossos referenciais teóricos permitiriam avançar, o tipo de contributo que poderiam ter e que não estava previsto inicialmente. É isto, exercitar a capacidade crítica, o debate, a controvérsia.

Cadernos: Trata-se de uma postura epistemológica que tem o seu lado ético.

Marianne: Certamente. Sobretudo a postura do princípio hipocrático, de fazer tudo também para não prejudicar ninguém. Isso é algo muito importante na formação de nossos estudantes porque, às vezes, eles têm certa dificuldade em gerir, porque é frequentemente a primeira experiência, e ficam envolvidos em projetos de responsáveis de empresas e não conseguem discernir muito bem as "armadilhas" desses envolvimentos, porque pode ser difícil mesmo.

Cadernos: Passando a uma temática que hoje nos interpela particularmente aqui: como você analisa a importância que a questão da competência vem adquirindo nos mundos do trabalho, na educação?

Marianne: Temos um capítulo do nosso livro que é quase todo consagrado à questão da formação profissional e contínua. E as questões relacionadas com as "competências" ocupam obviamente um lugar importante nessas páginas, sendo uma questão de partida a da (histórica) substituição progressiva, no mundo do trabalho, da noção de "qualificação" pela de "competência". Isto é: o abandono progressivo de uma prática de negociação entre parceiros sociais que sustentavam a definição de vários perfis profissionais existentes num determinado setor de produção e, considerando o tempo de formação necessário, assim como a experiência adquirida, os associavam a níveis de remuneração; e, hoje, a valorização de uma caracterização fortemente individualizada das qualidades efetivamente esperadas (expectáveis) de um operador pela entidade patronal. Marcelle Stroobants descreve muito bem essa evolução e seus efeitos na sua contribuição ao Dicionário de Laboreal ${ }^{16}$ - a revista que editamos desde 2005 na Universidade do Porto. Ela realça também a estreita associação entre a elaboração dos referenciais de competências e os processos de avaliação sistemática das performances e dos comportamentos dos trabalhadores que não deixam de amplificar a concorrência no seio do coletivo de trabalho. E, na educação - ou formação -, doravante, disse ela, "o resultado esperado é especificado, mas o meio de lá chegar continua obscuro". Penso que, face a esta generalização do uso dessa noção e sua particular ambiguidade, convém não esquecer a importância da abordagem sócio-histórica, a consideração das condições efetivas em que os

16 Stroobants, M. (2006). Competência. Laboreal, 2 (2), 78-79. 
profissionais acabam por desempenhar as suas funções e a mais valia da démarche de comparação que permite perceber que há, sempre, alternativas. Foi precisamente o que Marta Santos, professora da nossa equipe, trabalhou mais recentemente. Na revista Formation Emploi, acaba de publicar, com João Caramelo, colega nosso do departamento de Ciências da Educação, um artigo particularmente interessante, nomeadamente por ter associado uma perspectiva histórica com uma abordagem fina e concreta de um caso específico ${ }^{17}$. E, mais recentemente, temos também o artigo baseado na pesquisa de doutoramento de Joana Fernandes, orientada pela Marta e publicado na Laboreal ${ }^{18}$. Sublinho, reiterando o que já apontei relativamente à riqueza da dinâmica da academia brasileira: o percurso de Marta, e também de João, passaram por fases decisivas que ocorreram na universidade brasileira. João Caramelo realizou parte substancial da sua pesquisa doutoral em João Pessoa. A sua tese tematizou a formação de adultos, especialmente no âmbito de cooperativas de produção. Para tanto, contou com a interlocução do Professor José Francisco de Melo Neto, do Programa de Pós-Graduação em Educação da UFPB. E Marta participou num dos primeiros programas de colaboração, que coordenamos na Universidade do Porto, com universidades brasileiras e outras sul-americanas a partir de 1995. Tal colaboração ocorreu no âmbito do programa ALFA (Cooperação Acadêmica entre América Latina e União Europeia), financiado pela União Europeia, que pretendia valorizar a mobilidade dos doutorandos, neste caso, em Ergonomia ou Psicologia do Trabalho, provenientes de Portugal, da França, da Bélgica, do Brasil, da Venezuela e do México. Marta Santos esteve então na Universidade de Brasília, sob orientação de Júlia Abrahão, e com a sorte de lá se encontrar no mesmo momento que a investigadora cubana Albertina Mítjans, conhecida por ter feito a tese de doutorado em Moscou sobre Lev Vigotski e que liderou um extenso seminário essencialmente consagrado à sua obra. Isso se revelou importante, não apenas para a tese de doutoramento de Marta, mas ainda para os trabalhos posteriores que foram desenvolvidos. E continua a ser fundamental no seu diálogo com os colegas da Clínica da Atividade (nomeadamente com Bernard Prot), ou ainda com alguns colegas próximos da tradição da didática profissional, tendo recorrido de modo muito original ao contributo de Pierre Rabardel - relatado, aliás, no capítulo que redigiu para o nosso livro ${ }^{19}$.

Queria realçar ainda, aqui, que o último programa de colaboração da nossa equipe com universidades brasileiras foi o do intercâmbio de docentes, investigadores e doutorandos, realizado entre 2011 e 2014, no âmbito de um protocolo Capes-FCT (Fundação para a Ciência e a Tecnologia) e liderado no Brasil por Jussara Brito (Escola Nacional de Saúde Pública Sergio Arouca, Fundação Oswaldo Cruz).

Cadernos: E como se apresenta em Portugal e mais amplamente na Europa a questão da Saúde e Segurança no Trabalho, especialmente em face das mudanças que vêm ocorrendo no mundo do trabalho?

Marianne: Temos acompanhado essas questões graças a colaborações nacionais que temos tido. Fui professora, durante muitos anos, coadjuvada por Ricardo Vasconcelos, na Pósgraduação em Medicina do Trabalho da Faculdade de Medicina da Universidade do Porto. Liliana Cunha dá aulas de formação, na Faculdade de Engenharia, aos futuros técnicos em saúde e segurança do trabalho. Temos a nossa rede em Portugal, em cujo âmbito trabalhamos regularmente com médicos, engenheiros, ergonomistas e Ricardo Vasconcelos tem conseguido

17 Caramelo, J. \& Santos, M. (2013). Vers une reconnaissance des acquis de l'expérience au Portugal. Formation Emploi: Revue Française de Sciences Sociales, 122, 115-137.

18 Fernandes, J. \& Santos, M. (2014). A atividade dos formadores no reconhecimento e validação de adquiridos: a evolução de um instrumento a partir da atividade. Laboreal, 10 (1), 47-58.

19 Santos, M. (2013). Contribution d'un cadre théorique pour l'évaluation d'une action de formation en entreprise. In C. Teiger \& M. Lacomblez (Coord.), (Se) former pour transformer le travail: dynamiques de constructions d'une analyse critique du travail (pp. 564572). Québec/Bruxelles: Presses de l’Université Laval/PUL/European Trade Union Institute/ETUI. 
desenvolver projetos de intervenção em várias empresas ${ }^{20}$. São essas redes nacionais que ajudam a manter-nos informados sobre o que se passa em Portugal em matéria de Saúde e Segurança do Trabalho. E, articulados com outras redes a nível europeu, podemos ainda distinguir certas evoluções, mais claras em certos países - seja pelo melhor ou pelo pior. A colaboração que temos mantido com o ETUI (European Trade Union Institute, departamento da Confederação Europeia dos Sindicatos) tem-se também revelado bastante útil para este acompanhamento.

Cadernos: Na sua avaliação, em questão de riscos, adoecimento, acidentes de trabalho, esse quadro vem, ao que te parece, em Portugal e na Europa, se agravando ou tem havido uma melhoria? Quais têm sido as demandas, as queixas, os problemas que têm chegado aos sindicatos?

Marianne: Sustentando esse tipo de avaliação, há um grande inquérito europeu (Inquérito Europeu Sobre as Condições de Trabalho - IECT), regularmente realizado pela Fundação Europeia para Melhoria das Condições de Vida e de Trabalho (agência da União Europeia, com sede em Dublin). A fundação funciona em regime paritário, com supervisão constante de representantes dos vários estados-membros, das entidades empregadoras e dos sindicatos, tendo como missão desenvolver estudos que permitam monitorar a evolução dessas questões na Europa; e por conta disso tem desenvolvido pesquisas muito interessantes. É uma fonte de informação essencial. Aliás, no site dessa fundação, têm-se acessíveis muitos dos relatórios produzidos, alguns dos quais traduzidos em vários idiomas europeus, inclusive, em português. Esse grande inquérito permite traçar um panorama das evoluções das condições de trabalho e das questões de saúde e segurança no trabalho nos vários países-membros, apesar de ser um inquérito aplicado a amostras muito reduzidas, inclusive em Portugal - mesmo se é verdade que existe todo o cuidado para tentar obter uma amostra que seja a mais representativa possível. De qualquer modo, sabemos que uma das centrais sindicais portuguesas tem utilizado a estrutura desse inquérito para fazer a sua própria recolha de dados em algumas fábricas, estendendo assim o campo das amostras. E, igualmente, noutros países europeus existem organismos, pesquisadores, que também implementam inquéritos complementares, tentando melhorar a amplitude do inquérito europeu. Essa fundação publica regularmente uma síntese deste inquérito e aquilo que transparece como sendo as grandes tendências ${ }^{21}$ - que nem sempre são encorajadoras. Aliás, as pessoas que conhecemos no âmbito das organizações sindicais em Portugal reforçam este diagnóstico pessimista. Mas é também isso que as move no meio laboral. Por outro lado, o ETUI tem batalhado bastante, ultimamente, no âmbito da preparação dos textos programáticos da Comissão da União Europeia para os próximos anos, visando à definição das grandes linhas estratégicas no âmbito do denominado "Horizonte 2020", uma espécie de grande plano de desenvolvimento da União Europeia. Ora, as questões relacionadas com Saúde e Segurança do Trabalho estavam praticamente ausentes dos princípios orientadores estabelecidos inicialmente pela comissão. $\mathrm{O}$ argumento global era de que já se estudou muito tais dimensões e que agora existiriam outras prioridades. Todavia, esta posição acabou por desencadear debates interessantes, por vezes bem acesos. Nomeadamente porque, como sabemos, os conhecimentos técnicos e científicos não chegam por si só, e não raras vezes, o desfasamento (décalage/gap) entre aquilo que tais conhecimentos deveriam permitir realizar e o que acaba por caracterizar a implementação das medidas de prevenção nas

20 Ver nomeadamente: Lacomblez, M., Teiger, C., \& Vasconcelos, R. (2014). A ergonomia e o "paradigma da formação dos atores": uma parceria formadora com os protagonistas do trabalho. In L. Soboll \& P. F. Bendassolli (Orgs.), Métodos de pesquisa e intervenção em psicologia do trabalho: clínicas do trabalho (pp. 159-183). Brasil: Atlas.

21 Ver "Terceiro inquérito europeu às empresas: primeiras conclusões" em: http://eurofound.europa.eu/pt/publications/resume/2013/eu-member-states/working-conditions-labour-market-industrialrelations/third-european-company-survey-first-findings-resume 
situações de trabalho, revela-se quase sempre insatisfatório e por vezes trágico. Por essa razão, os nossos projetos constituem um verdadeiro desafio no que concerne a partilha de saberes, a sua melhor difusão e apropriação.

Cadernos: Muito obrigado!

\section{Endereço para correspondência}

lacomb@fpce.up.pt, anisiojsa@uol.com.br,

paulozamsouza@yahoo.com.br, thaisaugusta@gmail.com 